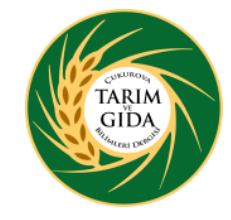

Derleme Makale

\title{
Bazı Doğal Antioksidanların Et ve Et Ürünlerinde Heterosiklik Aromatik Amin Oluşumu Üzerine Etkileri
}

\author{
Beyza ERDOĞAN, Özgül ÖZDESTAN OCAK*
}

\begin{abstract}
Özet
Gıdalarda 1sıl işlem uygulamalarıyla meydana gelen heterosiklik aromatik amin (HCA) bileşikleri gıdalarda bulunabilen en önemli toksik bileşiklerdendir. Bu sebeple HCA bileşikleri, gıdalarla birlikte tüketimiyle insan sağlığı açısından ciddi olumsuz etkilere sebep olabilecek potansiyele sahiptir. Bu bağlamda protein içeriği bakımından zengin olan et ve et ürünlerine uygulanacak işlemler, kontrollü bir şekilde gerçekleştirilmelidir. Özellikle pişirme sıcaklığının ve yönteminin HCA oluşumunu ve miktarını etkileyen en önemli faktörler olarak bilinmesiyle beraber ortamın antioksidan içeriğinin de HCA oluşumuna önemli düzeyde etkisi olduğu çeşitli çalışmalarla belirlenmiştir. Gıdaların pişirilmesi sırasında ortamda indirgen şekerler ile peptid, amino asit veya aminlerin birlikte bulunmasıyla, özellikle yüksek sıcaklıklarda HCA oluşumu açısından öncü olan Maillard reaksiyonu gerçekleşmektedir. Bu durumu önlemek amacıyla gıdalara eklenen doğal antioksidan maddelerin etkileri oldukça ilgi çekmektedir. Antioksidanlar, serbest radikal reaksiyonlarını önleyici özellikleri nedeniyle HCA oluşumuna karşı etkili inhibitörler haline gelmişlerdir. Bu derlemede, doğal antioksidan özellikteki maddelerin et ve et ürünlerinde kullanımının HCA oluşumu üzerine etkilerinin incelendiği çalışmalar özetlenmiştir.
\end{abstract}

Anahtar kelimeler: Heterosiklik aromatik amin, HCA, doğal katkı, et ve et ürünleri, antioksidan

\section{Effects of Some Natural Antioxidants on Heterocyclic Aromatic Amine Formation in Meat and Meat Products}

\begin{abstract}
Heterocyclic aromatic amine (HCA) compounds formed by heat treatment applications in foods are defined as the major class of toxic compounds. Therefore, HCA compounds have the potential to cause serious adverse effects on human health by intake with foods. In this context, the processes to be applied to meat and meat products that are rich in protein content should be carried out in a controlled way. Although the cooking temperature and method are known as the most important factors affecting the formation and amount of HCA, it has been determined by various studies that the antioxidant content of the medium has a significant effect on the formation of HCA. During the cooking of foods, the presence of reducing sugars and peptides, amino acids or amines occurs in the Maillard reaction which leads to the formation of HCA, particularly at elevated temperatures. In order to prevent this situation, the effects of natural antioxidants added to foods are of great interest. Antioxidants have become effective inhibitors of HCA formation because of their ability to prevent free radical reactions. In this review, the effects of the use of natural antioxidant substances in meat and meat products on HCA formation are summarized.
\end{abstract}

Keywords: Heterocyclic aromatic amine, HCA, natural additives, meat and meat products, antioxidant

ORCID ID (Yazar sirasına göre)

0000-0002-8834-1621, 0000-0003-0967-8865

Yayın Kuruluna Geliş Tarihi: 05.08.2019

Kabul Tarihi: 19.09.2019

Ege Üniversitesi, Mühendislik Fakültesi, Gıda Mühendisliği Bölümü, 35100, Bornova-İzmir

*E-mail: ozgul.ozdestan@ege.edu.tr 


\section{Bazı Doğal Antioksidanların Et ve Et Ürünlerinde Heterosiklik Aromatik Amin Oluşumu Üzerine Etkileri}

\section{Giriş}

Gıdaların lezzetini artırmak ve güvenli bir şekilde üretilmesini sağlamak amaciyla gidalara çeşitli uygulamalar yapılmaktadır. Bu uygulamalardan belki de en eski ve en bilineni pişirme işlemidir. Et ve et ürünlerinin, güvenli bir şekilde üretilmesini ve tüketilmesini sağlamak, istenen lezzet ve aroma bileşiklerini açığa çıkarmak amacıyla yaygın olarak pişirme işlemi uygulanmaktadır. Ancak bu işlemin uygun koşullarda gerçekleştirilmemesiyle gıdalarda istenmeyen bileşikler de oluşabilmektedir. Heterosiklik aromatik aminler (HCA'lar) et ve et ürünleri gibi zengin protein içeriğine sahip gıdaların yüksek sicaklıkta ve/veya uzun süreli gerçekleştirilen pişirme işlemiyle meydana gelen mutajenik ve kanserojenik etkilere sahip bileşiklerdir (Öz ve Kaya, 2007).

HCA'ların zararlı etkileri nedeniyle gidalarda oluşumunun önlenmesini amaçlayan çalışmalar yapılmaktadır. Genellikle $150^{\circ} \mathrm{C}$ ve üzeri sıcaklıklarda pişirme işlemlerinde amino asit, şeker ve kreatin bileşiklerinin öncülüğü ile HCA'ların oluşmaya başladığ bilinmektedir (Cheng ve ark., 2007). Bu bileşenler dışında gıdalarda HCA oluşumu ve miktarı; etin tipi, pişme sıcaklığı ve süresi, pişirme yöntemi ve kullanılan ekipmanlar gibi faktörlere bağlı olarak değişebilmektedir. Yapılan çalışmalara göre HCA'lar et ürünlerinin pişirilmesi sırasında ppb düzeyinde oluşmaktadır. Günümüze kadar toplamda 25'ten fazla farkl1 sayıda kanserojenik/mutajenik HCA tanımlanmıştır (Sugimura ve ark., 2004; Alaejos ve ark., 2008).

Gidalardaki lipit oksidasyonlarının HCA oluşumunda etkili olduğunun anlaşılmasıyla beraber özellikle et ve et ürünlerinde kullanılabilecek antioksidanların araştırılması önem kazanmıştır (Öz ve Kaya, 2007). Etlerde oksidasyonun önlenmesi veya azaltılmas amaciyla doğal ve sentetik antioksidanları̊ etkin bir şekilde kullanılabildiğ̣ bilinmektedir. Ancak sentetile antioksidanların toksik etkiye sahip olma riskleri ve güvenilirlik sorunları nedeniyle; doğal antioksidanların kullanımı daha çole tercih edilmektedir. Birçok gıda, et ve et ürünlerinde doğal antioksidan olarak kullanılabilir (Bastida ve ark., 2009).

HCA'ların Kimyasal Yapıları ve
Oluşumları

HCA'lar kimyasal sinıflarına göre aminoimidazoazoarenler (AIA) aminokarbolinler olarak sınıflandırılmaktadırlar. Isıl işlem görmüş gidalarda en önemli grubu oluşturan AIA'ler, 2-amino-3- metilimidazo[4,5-f]kinolin (IQ), 2-amino-3,4-dimetilimidazo[4,5-f]kinolin

(MeIQ), MeIQx, 2-amino-3,4,8trimetilimidazo[4,5-f]kinokzalin (DiMeIQx) ve PhIP'dır. IQ tipinde olmayan bileşikler veya pirolitik HCA'lar olarak da adlandırılan aminokarbolinler, pişirme ekipmanına bağlı olarak özellikle yüzey sıcaklığ $300^{\circ} \mathrm{C}$ ve üzerine çıktığında, proteinler ve aminoasitlerin pirolizi sonucu oluşmaktadır (Toribio ve ark., 2002).

Uluslararas1 Kanser Araştırma Merkezi (IARC), PhIP, IQ MeIQ, MeIQx, 2-amino9H-pirido [2,3-b ] indol (AaC) ve 2-amino-3metil-9H-pirido [2,3- b ] indol (MeAaC) bileşiklerini muhtemel insan kanserojenleri olarak tanımlamıştır (IARC, 1993). Özellikle PhIP'in; kızartma, 1zgara, mangal gibi yüksek sicaklık uygulamalarıyla HCA' lar arasinda en yüksek konsantrasyonlara ulaştığı belirlenmiştir (Zimmerli ve ark., 2001). Gıdalarda indirgen şekerler ile peptid, aminoasit veya amin bileșiklerinin beraber bulunması durumunda özellikle yüksek sicakliklardaki $\quad\left(150-300^{\circ} \mathrm{C}\right)$ pişirme işlemleriyle Maillard reaksiyonu gerçekleşebilmektedir. Reaksiyon sonucunda ortaya çıkan aminokarboniller ve aminoimidazoazoarenler, gidaların yapısında doğal olarak bulunan bu bileşikleri önemli kılmaktadır (Jägerstad ve ark., 1998).

Et ve et ürünlerinde HCA bileşiklerinin oluşumu ve miktarı;

Etin tipine (kırmızı et, tavuk, balık vs.)

Etin pH'sina,

Etin karbonhidrat, lipit, serbest aminoasit, kreatin içeriğine,

Lipit oksidasyonuna,

Etin pişirme koşullarına (pişirme yöntemi, pişme sıcaklığı ve süresi) 


\section{Bazı Doğal Antioksidanların Et ve Et Ürünlerinde Heterosiklik Aromatik Amin Oluşumu Üzerine Etkileri}

- Antioksidanlara $\begin{gathered}\text { bağlı } \\ \text { değişebilmektedir. (Szterk ve Waszkiewicz- }\end{gathered}$ Robak, 2014; Oz ve ark., 2007).

Kreatinin molekülü, HCA'nın tipik aminometilimidazo halkasını oluşturmaktadır. $\mathrm{Bu}$ nedenle kreatinin içeriği yüksek gidalarda HCA oluşumunun daha yüksek olduğu söylenmektedir (Jägerstad ve ark, 1991). Gıdanın lipit içeriğinin mutajenlerin oluşumu üzerine etkisi tam olarak bilinmemekle beraber; lipit içeriğinin düşük olması durumunda etin kreatin ve glukoz içeriğinin daha yüksek olduğundan bahsedilmiştir (Persson ve ark., 2008).
Şimdiye kadar et ve et ürünlerinde farklı yağ içeriğinin (Persson ve ark., 2008), marinasyon soslarının (Lan ve Chen, 2002) farklı pişirme yöntemlerinin ve 1 sıl işlem parametrelerinin $(\mathrm{Oz}$ ve ark., 2007; Keşkekoğlu ve Üren, 2014; Yang ve ark., 2019; Buła ve ark., 2019) ve antioksidan özelliğe sahip maddelerin kullanımının, HCA oluşuma etkileri araştırılmıştır. Çizelge 1'de HCA oluşumu üzerindeki etkileri araştırılan doğal antioksidan özellikteki maddeler gösterilmiştir.

Çizelge 1. Gıdalarda HCA oluşumu üzerine etkileri araştırılan doğal antioksidan kaynakları

\begin{tabular}{|c|c|c|c|c|c|}
\hline $\begin{array}{l}\text { Bitki } \\
\text { Ekstraktları }\end{array}$ & Referans & Baharatlar & Referans & Yağlar & Referans \\
\hline Biberiye & $\begin{array}{l}\text { Tsen ve ark., } \\
2006\end{array}$ & Karabiber & $\begin{array}{l}\text { Oz ve Kaya, } \\
2011 \mathrm{a} \text {; Zeng } \\
\text { ve ark., } 2017\end{array}$ & $\begin{array}{l}\text { Karanfil } \\
\text { tomurcuğu } \\
\text { yağ1 }\end{array}$ & $\begin{array}{l}\text { Rounds ve } \\
\text { ark., } 2012\end{array}$ \\
\hline Adaçayı & $\begin{array}{l}\text { Murkovic ve } \\
\text { ark., } 1998\end{array}$ & Kırmızıbiber & $\begin{array}{l}\text { Oz ve Kaya, } \\
2011 \text { b }\end{array}$ & Zeytinyağ1 & $\begin{array}{l}\text { Monti ve } \\
\text { ark., } \\
\text { 2001;Persson } \\
\text { ve ark., } 2003\end{array}$ \\
\hline $\begin{array}{l}\text { Üzüm } \\
\text { çekirdeği }\end{array}$ & $\begin{array}{l}\text { Gibis ve } \\
\text { Weiss, 2012; } \\
\text { Keskekoglu } \\
\text { ve Uren, } \\
2017\end{array}$ & Zerdeçal & $\begin{array}{l}\text { Puangsombat } \\
\text { ve ark., } 2011\end{array}$ & Kekik yağ1 & $\begin{array}{l}\text { Friedman ve } \\
\text { ark., } 2009\end{array}$ \\
\hline Yeşil çay & $\begin{array}{l}\text { Weisburger } \\
\text { ve ark., } 1994\end{array}$ & Kimyon & $\begin{array}{l}\text { Puangsombat } \\
\text { ve ark., } 2011\end{array}$ & Kolza yağ1 & $\begin{array}{l}\text { Persson ve } \\
\text { ark., } 2003\end{array}$ \\
\hline Enginar & $\begin{array}{l}\text { Tengilimoglu- } \\
\text { Metin ve } \\
\text { Kizil, 2017 }\end{array}$ & $\begin{array}{l}\text { Soğan ve } \\
\text { sarımsak } \\
\text { tozu }\end{array}$ & Gibis, 2007 & & \\
\hline Alıç & $\begin{array}{l}\text { Tengilimoglu- } \\
\text { Metin ve ark., } \\
2017\end{array}$ & $\begin{array}{l}\text { Tarçın ve } \\
\text { Karanfil }\end{array}$ & $\begin{array}{l}\text { Damašius ve } \\
\text { ark., } 2011\end{array}$ & & \\
\hline Elma kabuğu & $\begin{array}{l}\text { Sabally ve } \\
\text { ark., } 2016\end{array}$ & & & & \\
\hline $\begin{array}{l}\text { Ananas, } \\
\text { Elma }\end{array}$ & Cheng, 2007 & & & & \\
\hline
\end{tabular}

\section{HCA'ların Sağlık Üzerine Etkileri}

Son y1llarda, et ve et ürünlerinin tüketimindeki artış ile kardiyovasküler ve gastrointestinal hastalıklarla ilişkilendirilen şişmanlık artışı ile arasında bir bağlantı olduğu düşünülmektedir. Epidemiyolik çalışmalar HCA bileşiklerinin gıdalarla beraber vücuda alınmasıyla çeşitli kanser türlerine sebep olabilecek güçlü mutajenik ve kanserojenik etkilere sahip olduğunu göstermiştir (Chiang ve Quek, 2017). Bu bileşikler vücutta beklenmeyen DNA sentezlerine sebep olurlar ve mutajenikkanserojenik potansiyeli nitrozaminler, aflatoksin $B 1$ ve benzo $[\alpha]$ piren gibi toksik 


\section{Bazı Doğal Antioksidanların Et ve Et Ürünlerinde Heterosiklik Aromatik Amin Oluşumu Üzerine Etkileri}

bileşenlere oranla on kat daha yüksektir (Pezdirc ve ark., 2013; Püssa, 2013).

Heterosiklik aminlerin fareler, maymunlar gibi insan olmayan primatların çeşitli organlarında tümörojenik etkiye sahip olduğu görülmüştür (Wakabayashi ve ark., 1992; Adamson ve ark., 1994). Test edilen çoğu HCA bileşiğin karaciğer, kolon, akciğer, cilt, ağız ve mide gibi hedef organları olan deney hayvanlarında kanserojen olduğu kanıtlanmıştır (Püssa, 2013). Bazı HCA bileşikleri, in vitro çalışmalarda kolon kanseri başta olmak üzere, meme, mide, pankreas ve prostat kanseri gibi birçok kanserle ilişskilendirilmiştir (Sugimura ve ark., 2004; Alaejos ve ark., 2008).

Çoğu kanserojen doğrudan mutajenik aktiviteye sahip olamayacağı için vücutta aktivasyonlarının sağlanması sırasında metabolik enzimlere ihtiyaç vardır. HCA bileşikleri ince bağırsakta emilir ve karaciğere taşınarak aktive olur. Burada sitokrom enzimi varlığında DNA'nın hasar görmesiyle sonuçlanan bir dizi reaksiyon gerçekleşerek mutasyona sebep olur (Barzegar ve ark., 2019).

İnsanların HCA'lara maruz kalma seviyeleri yiyecek türüne, pişirme yöntemi gibi faktörlerle beraber porsiyon büyüklüğü ve alım sıklığına da bağlıdır (Skog, 1993). Wolk (2017), günlük $50 \mathrm{~g}$ işlenmiş et tüketiminin yaklaşık olarak prostat kanserini \%4, kolon kanserini \%18, meme kanserini \%9 ve pankreas kanserini \%19 oranında artırabileceğini belirtmiştir. Heterosiklik aromatik aminlerin günlük kabul edilebilir alım miktarı için üst sınır $15 \mu \mathrm{g}$ olarak belirlenmiştir (Felton ve ark., 2000).

\section{HCA'ların Tespit Yöntemleri}

Gıdalarda HCA bileşiklerinin tespit edilebilmesi için öncelikle etkin bir saflaştırma işlemi gerçekleştirilmelidir. $\mathrm{Bu}$ amaçla örnek hazırlama aşamasında;

- $\quad$ Katı faz ektsraksiyonu (SPE)

- $\quad$ Katı faz mikro ekstraksiyonu (SPME)

- $\quad$ Sivi-sivi ekstraksiyonu (LLE)

- $\quad$ Süperkritik siv1 ekstraksiyonu (SFE)

- Basınçlı sıvı ekstraksiyonu (PLE),

- Mikrodalga destekli ekstraksiyon gibi saflaştırma yöntemleri kullanılmaktadır (Pais ve Knize, 2000; Cárdenes ve ark., 2004; Barzegar ve ark., 2019).

Gıda matrisinin oldukça karmaşık yapıda olması ve HCA'ların genellikle düşük konsantrasyonlarda (ng/g) bulunmas1 sebebiyle gidalarda tespit edilebilmeleri için seçici ve hassas kromatografik tekniklere ihtiyaç duyulmaktadır (Krach ve Sontag, 2000). Bu amaçla, en yaygın kullanılan kromatografik tekniklerin başında HPLC (Yüksek Performanslı Sıvı Kromatografisi) gelmektedir. HPLC ile farklı dedektör sistemlerinin kullanılmasiyla analizlerde istenilen hassasiyet ve seçicilik sağlanabilir. Fluoresans (F), ultraviyole (UV), elektrokimyasal (ED) ve kütle spektrometresi (MS) dedektörleri bu amaçla yaygın olarak kullanılmaktadır (Pais ve Knize, 2000). Özellikle HPLC-UV çok düşük seviyelerdeki HCA'ların tespitinde yetersiz olduğundan son yıllarda, HPLC-MS iyi ayrım sağlaması, yüksek hassasiyeti ve seçiciliği sayesinde karmaşık matrislerde güvenilir sonuçlar vermesiyle dikkat çekmektedir (Krach ve Sontag, 2000). HCA bileşiklerinin tespitinde kullanılan diğer yöntemler, gaz kromatografisi (GC), kapiler elektroforez (CE) ve ELISA (Enzyme-linked immunosorbent assay)'dır. Yöntemlerin tespit sınırları analiz edilen bileşiğe ve örnek saflığına bağlı olarak 0.01-50ng/g'dır ve çoğu yöntemle tek seferde 10-15 farklı HCA bileşiği tespit edilebilir (Toribio ve ark., 2002).

\section{Doğal Antioksidan Maddeler}

Gıdaların yapısında sağlık üzerinde olumlu etkileriyle bilinen ve özellikle son y1llarda dikkat çeken karotenoidler, vitaminler, flavanoidler gibi doğal antioksidan özelliğe sahip pek çok bileşen bulunmaktadır. Şimdiye kadar askorbik asit, $\alpha$-tokoferol, flavanoidler, ellagik asit, meyve ve sebzeler, soya, çay, zeytinyağ1 ve baharatlar gibi doğal antioksidanların HCA oluşumuna etkileri araştırılmış ve çeşitli model sistemlerle gösterilmiştir (Vitaglione ve Fogliano, 2004). Laboratuvar çalışmalarıyla aminoasit, kreatin ve karbonhidrat bulunan model sistemin hidrokinon varlığında 1sitılmasıyla beraber mutajenik aktivitede artış gerçekleştiği 


\section{Bazı Doğal Antioksidanların Et ve Et Ürünlerinde Heterosiklik Aromatik Amin Oluşumu Üzerine Etkileri}

görülmüştür. Ortama antioksidan ilavesi MeIQx gibi bazı HCA bileşiklerinin oluşumunu artırırken, flavonlar azaltıcı etki göstermiştir. Adaçayı ve biberiye gibi baharatlar içerdikleri rosmanol, karnosol, kanosik asit gibi aktif bileşenler sayesinde antioksidan aktiviteye sahiptirler (Skog ve Jägerstad, 1993; Murkovic ve ark., 1998).

Gıdaların karmaşık yapısı nedeniyle, birçok araştırmacı HCA'nın oluşum mekanizmasını incelemek için model sistemler kullanmıştır. Ancak model çalışmaları, öncüller ve oluşan reaksiyon ürünleri hakkında temel bilgileri sağlayabilse de, sonuçlar gida sistemlerinden farklı olabileceği düşünülmüştür (Lan ve ark., 2004).

Kikugawa (1999), bir model sistemi kullanarak bütillenmiş hidroksianisol (BHA), sesamol, epigallokateşin gallat (EGCG), propil gallat (PG) ve esculetin gibi bileşiklerin imidazokinokzalin tipi mutajenlerin oluşumu üzerindeki etkisini araştırmıştır. Glukoz, glisin ve kreatinin içeren sulu ortam 1sıtılarak fenolik antioksidanlar eklenmiş ve tüm fenolik antioksidanların mutajenitenin oluşumunu doza bağlı bir șekilde inhibe edebileceği belirlenmiştir. Bu bağlamda aynı çalışmada, yeşil çay ekstraktı ve EGCG'nin antioksidan etkileri model sistemi yerine palamut balığı kullanılarak incelenmiş ve mutajen oluşumunun etkin bir şekilde azaldığ 1 görülmüştür.

Domates ekstraktından elde edilen karotenoidlerin kreatin, glisin ve glukozdan oluşan sulu bir kimyasal model sistemi ve et suyu model sistemine eklenmesiyle HCA oluşumuna etkileri karşılaştırılmıştır. Karotenoid ekstraktının 1000 ppm konsantrasyonda kullanımı kimyasal model sisteminde \%36 IQx ve \%11 MeIQx; et suyu sisteminde \%13 MeIQx, \%5 4,8-DiMeIQx inhibisyonu sağlamıştır. Domatesin ana flavonoidi olan kuersetinin et suyu model sisteminde $10 \mathrm{ppm}$ kullanımının MeIQx oluşumunu \%9-\%57 aralığında inhibe ettiği belirlenmiştir (Vitaglione ve ark., 2002).

Zeytinyağındaki fenolik bileşiklerin model sistemlerde ve gida ortamında önemli oranda HCA inhibisyonu sağladığ kanıtlanmıştır (Monti ve ark., 2001). Konsantrasyona bağlı olarak değişiklik gözlense de, özellikle çay ve zeytinyağından elde edilen fenolik bileşiklerin pro- ve antioksidan etkilerinden dolayı HCA oluşumuna en etkili doğal antioksidanlar olabileceği savunulmuştur (Vitaglione ve Fogliano, 2004). Sarımsak ve soğanla marinasyonun sistein, asetilsistein ve glutatyon gibi bileşikler sayesinde HCA oluşumunu azaltıcı etkisi olduğu bildirilmiştir (Gibis, 2007).

Fenolik bileşiklerin ve gıda özütlerinin HCA oluşumunu önlemek amacıyla kullanımıyla beraber şarap ve bira gibi antioksidan içeriği yüksek alkollü içeceklerle marinasyonun etkileri de araştırılmaya başlamıștır. Dana etinin bira, şarap ve çeşitli baharatlarla marinasyonuyla PhIP başta olmak üzere HCA bileşiklerinin oluşumunun önemli aralıklarda inhibe edildiği görülmüş ve bu etkinin yüksek polifenol içeriğinden kaynaklanabileceği düşünülmüştür (Viegas ve ark., 2012).

\section{Doğal Antioksidan Özellikteki Katkıların Et ve Et Ürünlerinde HCA Oluşumunu Önlemek Üzere Kullanımı}

Vitaminler (C, E ve A vitaminleri), flavonoidler, karotenoidler ve polifenoller, gıdalarda bulunan ve vücuda alınması ile sağlık üzerinde olumsuz etkiye sebep olan radikallerden korunmayı sağlayan başlıca doğal antioksidanlar olarak bilinmektedirler (Güçlü ve ark., 2009). Günümüzde meyveler, tohumlar, çeşitli baharatlar ile bunlardan elde edilen ekstraktlar ve yağlar, doğal antioksidan etkileri sayesinde et ve et ürünlerinde yaygın olarak kullanılmaktadır (Bastida ve ark., 2009). Antioksidanlar, ortamdaki serbest radikallerin oluşumunu engelleyerek veya mevcut uzaklaştırarak HCA'ların oluşumunu önleyebilirler (Gibis ve Weiss, 2012). Doğal antioksidanların antioksidan özelliklerinin, moleküler yapılarıyla ilişkili olduğu bilinmektedir (Pannala ve ark., 2001). Bitkisel ekstraktlar başta olmak üzere bu antioksidanların genellikle HCA oluşumuna etkileri sayesinde insanlarda kanser riskini azaltıc1 potansiyele sahip oldukları belirtilmiştir (Rounds ve ark., 2012). Ancak kullanılacak katkı maddesinin, lezzet başta olmak üzere gıdanın duyusal özelliklerini olumsuz etkilememesine dikkat edilmelidir. Rounds ve arkadaşları (2012), çeşitli bitkisel ekstraktların, baharatların ve bitkisel yağların 


\section{Bazı Doğal Antioksidanların Et ve Et Ürünlerinde Heterosiklik Aromatik Amin Oluşumu Üzerine Etkileri}

sığır köftelerinde HCA oluşumunu belirlemek için bir çalışma yapmışlardır. Dana köftelerine $\% 1(\mathrm{a} / \mathrm{a})^{\prime}$ lik konsantrasyonda esansiyel yağlar ve $\% 5(\mathrm{a} / \mathrm{a})$ oranında bitkisel ekstraktlar ve baharatlar eklenerek $200^{\circ} \mathrm{C}$ izgarada pişirilmiştir. Yapılan analizlere göre köftelerde MelQx oluşumunda azalma, bitkisel ekstraklarda; \%79.5 (zeytin), \%76.1 (elma kabuğu), \%31.4 (yeşil çay), \%50.4 (üzüm çekirdeği), toz baharatlarda; \%78.0 (soğan), \%68.9 (paprika), \%66.2 (sarımsak), \%49.5 (kekik otu), \%48.6 (zerdeçal), \%24.2 (kimyon), esansiyel yağda; \%35.0 (karanfil tomurcuğu yağı) olarak bulunmuştur. PhIP oluşumundaki azalma ise; bitkisel ekstraklarda; \%84.3 (zeytin), \%82.1 (elma kabuğu), \%86.0 (yeşil çay), \%78.9 (üzüm çekirdeği), toz baharatlarda; \%94.3 (soğan), \%87.2 (paprika), \%85.0 (sarımsak), \%85.4 (kekik otu), \%73.6 (zerdeçal), \%51.7 (kimyon), esansiyel yağda; \%52.1 (karanfil tomurcuğu yağı) oranında belirlenmiştir. Genel olarak bitkisel ekstraktların toz baharatlarla kıyaslandığında HCA oluşumunu daha yüksek oranda etkilediği belirtilmiştir.

$\mathrm{Oz}$ ve Kaya (2011a), karabiberin yüksek yă içeriğine (\%30) sahip köftelerde HCA oluşumuna etkisi araştırmışlardır. Bu amaçla dana köftelerine \%1 (a/a) karabiber eklenerek $175^{\circ} \mathrm{C}, 200^{\circ} \mathrm{C}$ ve $225^{\circ} \mathrm{C}$ 'de kizartılmıştır. En yüksek miktarda $\mathrm{HCA}, 225^{\circ} \mathrm{C}$ 'de $31.80 \mathrm{ng} / \mathrm{g}$ (PhIP) saptanırken MeIQx hiçbir örnek grubunda tespit edilmemiştir. Toplam HCA oluşumu \%12-100 aralığında inhibe edilmiştir. Başka bir çalışmada (Zeng ve ark., 2017) karabiber $(\% 0.05, \% 0.10$, ve $\% 0.15$, $\mathrm{g} / \mathrm{g})$ ve piperinin $(\% 0.005, \% 0.010$ ve $\% 0.015$, $\mathrm{g} / \mathrm{g}$ ) dana köftelerine eklenmesiyle HCA oluşumuna etkileri karşılaștırılmıştır ve piperinin analiz edilen tüm HCA'ların ( $\mathrm{PhIP}$, IQx, MeIQx, 4-DiMeIQx, harman ve norharman) oluşumunu inhibisyonda daha etkili olduğu belirlenmiştir. Toplam HCA oluşumu $225^{\circ} \mathrm{C}$ 'de pişirilen köftelerde konsantrasyona göre sırasıyla karabiber içeren grubun $\% 42, \% 34, \% 25$ ve piperin içeren grubun \%62, \%60 \%56 oranında inhibe olduğu tespit edilmiştir.

Gibis ve Weiss (2012) yaptıkları bir çalışmada, biberiye ve üzüm çekirdeği ekstraktlarının dana köftelerinde HCA üzerine etkisini araştırmışlardır. Köfteler ayrı ayrı biberiye ve üzüm çekirdeği ekstraktları ile marine edilip kızartılmışlardır. Kızartılan köftelerde yapılan analizler sonucunda MelQx ve $\mathrm{PhIP}$,'de \%57-\%90 aralığında azalma tespit edilirken, norharman ve harman seviyeleri de düşük çıkmıştır. Biberiye ekstraktının antioksidan kapasitesinin üzüm çekirdeği ekstraktının yarısı kadar olduğu anlaşılmıştır. Keşkekoğlu ve Üren (2014), dört farklı yöntemle (firında, 1zgarada, mangalda ve yağda) pișirilen dana ve tavuk eti köftelerinde nar çekirdeği ekstraktının etkilerini incelemişlerdir. Köftelere eklenen $\% 0.5(\mathrm{a} / \mathrm{a})$ nar çekirdeği ekstraktının en yüksek inhibe edici etkiyi derin yağda kızartılan örnek grubunda gösterdiği görülmüştür. Dana eti köftelerinde en yüksek inhibe edici etki PhIP, norharman, harman, IQ ve MelQx için sirasiyla $\% 68, \% 24, \% 18, \% 45$ ve $\% 57$ iken, tavuk eti köfteleri için sırasıyla; \%75, \%57, $\% 28, \% 46$ ve $\% 49$ olarak bulunmuştur. Dana köftelerinde toplam HCA oluşumu pişirme yöntemlerine göre mangalda $\% 39$ ve derin yağda $\% 46$ oranında azalmıştır.

Benzer bir çalışmada üzüm çekirdeği ekstraktının farklı yöntemlerle pişirilen köfteler üzerinde HCA oluşumuna etkisi araştırılmıştır. Dana eti köftelerinde en yüksek inhibe edici etki PhIP, norharman, IQ ve MelQx için sırasıyla $\% 65, \% 69, \% 65$ ve $\% 59$ iken, tavuk eti köfteleri için sırasıyla; \%73, $\% 31, \% 52$ ve $\% 37$ olarak bulunmuştur. Pişirme yöntemlerine göre dana köftelerinde toplam HCA seviyesinin hem mangalda hem de firında \%65 oranında azaldığg görülmüştür (Keşkekoğlu ve Üren, 2017).

Şimdiye kadar et ve et ürünlerinde kullanılan çeşitli katkıların HCA oluşumu üzerine etkilerinin araştırıldığı bazı çalışmalar ve elde edilen sonuçlar Çizelge 2'de verilmiştir. Et ve et ürünleri dişında peynir (Naccari ve ark., 2009), bira (Manabe ve ark., 1993) kırmızı ve beyaz şarap (Richling ve ark., 1997) gida aromaları (Schwarzenbach ve Gubler, 1992) ve tablet bulyonlarda (Krach ve Sontag, 2000) HCA bileşiklerinin oluşumu araştırılmıştır. 


\section{Bazı Doğal Antioksidanların Et ve Et Ürünlerinde Heterosiklik Aromatik Amin Oluşumu Üzerine Etkileri}

Çizelge 2. Gıdalarda kullanılan çeşitli katkıların HCA oluşumu üzerine etkileri ile ilgili çalışmalar

\begin{tabular}{|c|c|c|c|}
\hline Katkı & $\begin{array}{l}\text { Kullanılan Örnekler ve } \\
\text { Uygulanan İșlemler }\end{array}$ & Çalışmada EIde Edilen Sonuçlar & Referans \\
\hline $\begin{array}{l}\text { Biberiye, adaçayı, } \\
\text { kekik ve sarımsak }\end{array}$ & $\begin{array}{l}\text { Dana eti örneklerine } \\
\text { eklenip } 180^{\circ} \mathrm{C} \text { 'de } 20 \mathrm{dk} \\
\text { kızartılmışlardır. }\end{array}$ & $\begin{array}{l}\text { Yapılan analizler örneklerde; } 13.2 \mu \mathrm{g} \\
/ \mathrm{kg} \text { MeIQx, } 10.2 \mu \mathrm{g} / \mathrm{kg} \mathrm{IQ}, 2.26 \mu \mathrm{g} / \\
\mathrm{kg} \mathrm{4,8-DiMeIQx}, 2.46 \mu \mathrm{g} / \mathrm{kg} \mathrm{MeIQ} \\
\text { ve } 5.28 \mu \mathrm{g} / \mathrm{kg} \mathrm{PhIP} \mathrm{oluştuğunu} \\
\text { göstermiştir. Kullanılan baharatlar } \\
\text { kontrol grubuna göre HCA oranını } \\
\text { \%60 azaltmıştır. }\end{array}$ & \begin{tabular}{l}
\multicolumn{2}{l}{ Murkovic } \\
ve ark., \\
1998
\end{tabular} \\
\hline $\begin{array}{lr}\text { Domateslerden } & \text { elde } \\
\text { edilen } & \text { karotenoid } \\
\text { ekstraktı } & \end{array}$ & Dana eti suyu & $\begin{array}{l}\text { Et suyu model sisteminde kullanılan } \\
1000 \text { ppm konsantrasyonundaki } \\
\text { karotenoid ekstraktının, MelQx } \\
\text { oluşumunun } \% 13 \text { ve } 4,8 \text {-DiMeIQx } \\
\text { oluşumunun } \% 5 \text { oranında azaltıldığ1 } \\
\text { belirlenmiştir. }\end{array}$ & $\begin{array}{l}\text { Vitaglione } \\
\text { ve ark., } \\
2002\end{array}$ \\
\hline $\begin{array}{l}\text { Zeytinyağı ve kolza } \\
\text { yağı }\end{array}$ & $\begin{array}{lr}\begin{array}{l}\text { Hamburger } \\
\text { farklı yağlar }\end{array} & \begin{array}{r}\text { köfteleri, } \\
\text { (rafine }\end{array} \\
\begin{array}{l}\text { zeytin yağ1, } \\
\text { zeytinyağ1, fenollerden } \\
\text { arındırılmış }\end{array} & \text { sızma } \\
\begin{array}{l}\text { zeytinyağ1, } \\
\text { ekstraktı }\end{array} & \text { biberiye } \\
\text { zeytinyağ1 ve } & \text { içeren } \\
\text { tohumu } & \text { kolza } \\
\text { kullanılarak } & \text { yağı) } \\
\text { k1zartılmışlardır. } & 200^{\circ} \mathrm{C} \\
\end{array}$ & $\begin{array}{l}\text { Köftelerde } 12 \text { farklı HCA tespit } \\
\text { edilmiştir. Bunlardan MeIQx, 4,8- } \\
\text { DiMeIQx, PhIP, harman ve } \\
\text { norharman zeytinyağında kızartılmış } \\
\text { bütün köftelerde belirlenmiştir. Sızma } \\
\text { zeytinyağındaki HCA oluşumu, rafine } \\
\text { zeytinyağına göre daha az meydana } \\
\text { gelmiştir ve bu durumun } \\
\text { zeytinyağındaki fenollerden } \\
\text { kaynaklandığı belirtilmiştir. }\end{array}$ & $\begin{array}{l}\text { Persson ve } \\
\text { ark., } 2003\end{array}$ \\
\hline 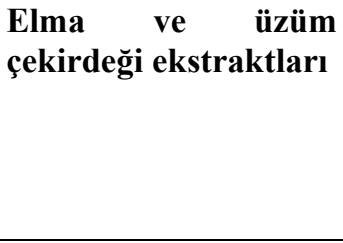 & 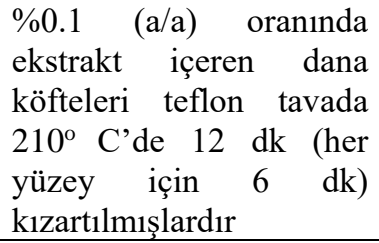 & $\begin{array}{l}\text { Ekstraktlar, hem ayrı ayrı MelQx, } \\
\text { DiMelQx ve PhIP ‘in hem de toplam } \\
\text { HCA içeriğinin azalmasını (kontrol } \\
\text { grubuna göre yaklaşı \% } 70 \text { oranında) } \\
\text { sağlamışlardır. }\end{array}$ & $\begin{array}{l}\text { Cheng ve } \\
\text { ark., } 2007\end{array}$ \\
\hline Bira & $\begin{array}{l}\text { Dana etleri, } 18^{\circ} \mathrm{C}^{\prime} \mathrm{de} 1,2, \\
4 \text { ve } 6 \text { saat marine edilip } \\
\text { teflon tavada } 180- \\
200^{\circ} \mathrm{C}^{\prime} \text { de her yüzeyi } 4 \mathrm{dk} \\
\text { pişirilmiştir. }\end{array}$ & $\begin{array}{l}\text { Örneklerin PhIP ve MelQx seviyeleri } \\
\text { her iki marinasyon işleminde de (bira } \\
\text { ve şarap) sırasıyla \%88 ve } \% 40 \\
\text { civarında azalmıştır. }\end{array}$ & $\begin{array}{l}\text { Melo ve } \\
\text { ark., } 2008\end{array}$ \\
\hline $\begin{array}{l}\text { Karvakrol (Kekik } \\
\text { yağının bileşeni) }\end{array}$ & $\begin{array}{l}\text { \%1 karvakrol içeren dana } \\
\text { köfteler elektrikli tavada, } \\
\text { merkez sicaklıkları } 65,70 \\
\text { ve } 80{ }^{\circ} C^{\prime} \text { ye ulaşıncaya } \\
\text { dek pişirilmişlerdir. }\end{array}$ & $\begin{array}{l}\text { HCA oluşumunda en yüksek orandaki } \\
\text { azalmalar } 70^{\circ} \mathrm{C} \text { sıcaklıkta } \\
\text { gerçekleşmiştir. İnhibisyon oranları } \\
\text { PhIP, MelQx ve MelQ'da sirasıyla; } \\
\% 78, \% 72 \quad \text { ve } \% 58 \text { olarak } \\
\text { bulunmuştur. }\end{array}$ & \begin{tabular}{l}
\multicolumn{2}{l}{ Friedman } \\
ve ark., \\
2009
\end{tabular} \\
\hline $\begin{array}{l}\text { Biberiye ekstraktları } \\
\text { (5 farklı yöntemle elde } \\
\text { edilmiş) }\end{array}$ & 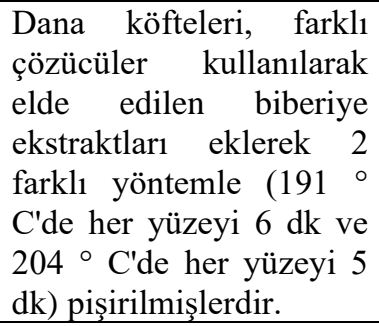 & $\begin{array}{l}\text { Köfte } \\
\text { tamamında örneklerinin } \\
\text { oluşumunun önemli oranda azaldığ1 } \\
\text { görülmüştür. \%20'lik etanol çözeltisi } \\
\text { kullanımının en yüksek inhibisyon } \\
\text { etkisine (\%91.7 MelQx, \%85.3 PhIP) } \\
\text { sahip olduğu tespit edilmiştir. }\end{array}$ & $\begin{array}{l}\text { Puangsom } \\
\text { bat ve } \\
\text { Smith, } \\
2010\end{array}$ \\
\hline Kırmızıbiber & $\begin{array}{l}\% 1 \quad(a / a) \text { kirmizibiber } \\
\text { içeren dana etleri, } 175^{\circ} \mathrm{C} \text {, }\end{array}$ & \begin{tabular}{lrrr} 
Kırmızıbiber & \multicolumn{2}{r}{ içermeyen } & kontrol \\
grubunda en & düşük & miktarın \\
$\left(225^{\circ} \mathrm{C}^{\prime} \mathrm{de}\right)$ & 2.63 & $\mathrm{ng} / \mathrm{g}$ & olduğu \\
\end{tabular} & $\begin{array}{l}\mathrm{Oz} \\
\text { Kaya, } \\
2011 \mathrm{~b}\end{array}$ \\
\hline
\end{tabular}


Bazı Doğal Antioksidanların Et ve Et Ürünlerinde Heterosiklik Aromatik Amin Oluşumu Üzerine Etkileri

\begin{tabular}{|c|c|c|c|}
\hline & $\begin{array}{l}200^{\circ} \mathrm{C} \text { ve } 225^{\circ} \mathrm{C}^{\prime} \mathrm{de} \\
\text { kıartılmışlardır. }\end{array}$ & $\begin{array}{l}\text { görülmüştür. Kırmızıbiber içeren } \\
\text { örnek grubunda ise en yüksek } \\
\text { miktarın }\left(225^{\circ} \mathrm{C} \text { 'de }\right) 0.64 \mathrm{ng} / \mathrm{g} \text { olduğu } \\
\text { belirlenmiştir. Toplam HCA oluşumu } \\
\% 75-100 \text { aralığında inhibe edilmiştir. }\end{array}$ & \\
\hline $\begin{array}{l}\text { Zerdeçal, zencefil } \\
\text { çiçeği ve limon otu }\end{array}$ & $\begin{array}{l}\text { Farklı oranlarda } \\
\text { baharatlarla marine } \\
\text { edilen } 1 \text { gr dana } \\
\text { etlerinden yapılmış satay } \\
\text { örnekleri (Güneydoğu } \\
\text { Asya yemeği), } 70^{\circ} \mathrm{C} \text { ve } \\
80^{\circ} \mathrm{C} \text { sicaklıklarda } 1 \text { zgara } \\
\text { edilmiştir. }\end{array}$ & 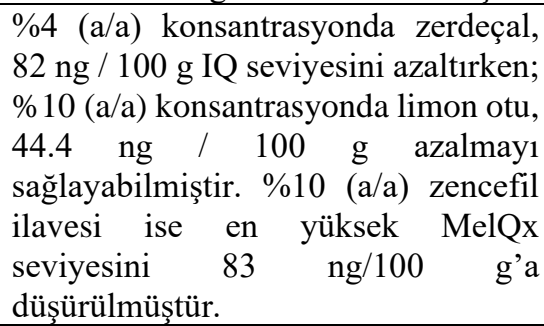 & $\begin{array}{l}\text { Jinap ve } \\
\text { ark., } 2015\end{array}$ \\
\hline Alıç eksraktı & $\begin{array}{l}\text { Farklı oranlarda ekstrakt } \\
\text { içeren dana ve tavuk } \\
\text { göğüs etleri, tavada ve } \\
\text { firında üç farklı } \\
\text { sicaklıkta }(150,200 \text { ve } \\
\left.250^{\circ} \mathrm{C}\right) \text { pişirilmişlerdir }\end{array}$ & $\begin{array}{l}\text { En yüksek oranda toplam HCA } \\
\text { inhibisyonun, \%0.5 ekstrakt içeren } \\
\text { etlerde gerçekleştiği belirlenmiştir. } \\
\text { Ekstrakt eklenen dana etlerinde } \\
\text { toplam HCA oluşumu } \% 20-100 \\
\text { aralığında, tavuk göğüs etlerinde ise } \\
\% 12-100 \text { aralığında azalmıştır. }\end{array}$ & $\begin{array}{l}\text { Tengilimo } \\
\text { glu-Metin } \\
\text { ve ark., } \\
2017\end{array}$ \\
\hline Enginar ekstraktı & $\begin{array}{l}\text { Dana eti ve tavuk gögüs } \\
\text { etlerine farklı oranlarda } \\
\text { ekstraktlar eklenip, } \\
\text { tavada ve firında üç } \\
\text { farklı sıcaklıkta (150, } \\
200 \text { ve } \\
\left.250^{\circ} \mathrm{C}\right) \text { pişirilmiştir. }\end{array}$ & 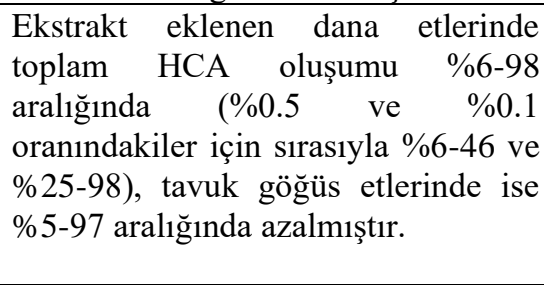 & $\begin{array}{l}\text { Tengilimo } \\
\text { glu-Metin } \\
\text { ve Kizil, } \\
2017\end{array}$ \\
\hline Karanfil ve tarçın & $\begin{array}{l}\text { Farklı yağ içeriklerine } \\
\text { (sığır yağı, donyağı, deri } \\
\text { altı ve kuyruk yağı) sahip } \\
\text { sucuk örneklerine } \\
\text { baharatlar katılıp } 24-48 \\
\text { saat fermente edildikten } \\
\text { sonra } 60^{\circ} \mathrm{C} \text { 'de } 1 \text { sıl işlem } \\
\text { uygulanmıştır. }\end{array}$ & $\begin{array}{l}\text { Tüm HCA'lar arasında en yüksek } \\
\text { miktarda oluşan IQ olmuştur. S1 ğır } \\
\text { yağı ve \%0.5 tarçın içeren örneklerin } \\
\text { IQ seviyesi } 5.96 \mathrm{ng} \text { /g tespit edilmiştir. } \\
\text { Baharat eklenen örneklerden sı ğır } \\
\text { yağ1 ve iç yağı içeren gruplarda HCA } \\
\text { oluşumu önemli miktarda artarken, } \\
\% 0.5 \text { tarçın eklenen ve deri altı yağ } 1 \\
\text { içeren grupta toplam HCA } \\
\text { oluşumunun en az olduğu } \\
\text { görülmüştür. }\end{array}$ & $\begin{array}{l}\text { Unal ve } \\
\text { ark., } 2018\end{array}$ \\
\hline $\begin{array}{l}\text { Zeytin } \\
\text { ekstraktı }\end{array}$ & $\begin{array}{l}\text { Farklı oranlarda }(\% 0, \\
\% 0.25, \% 0.5, \% 1, \% 2) \\
\text { ekstrakt eklenen somon } \\
\text { balıkları, } 180^{\circ} \mathrm{C} \text { ve } 220^{\circ} \mathrm{C} \\
\text { sicaklıklarda tavada } \\
\text { pişirilmiştir. }\end{array}$ & $\begin{array}{l}\text { Pişmiş örneklerde toplam HCA } \\
\text { miktarı } 0.81-4.03 \mathrm{ng} / \mathrm{g} \text { aralığında } \\
\text { bulunmuştur. Somon örneklerine } \\
\% 0.25 \text { ve } \% 1 \text { oranında eklenen zeytin } \\
\text { yaprağ eksraktının, HCA oluşumunu } \\
\% 3.87-77.69 \text { aralığında azalttığ } 1 \\
\text { belirlenmiştir. }\end{array}$ & $\begin{array}{l}\text { Macit, } \\
2018\end{array}$ \\
\hline $\begin{array}{l}\text { Reishi } \\
\text { ekstraktı }\end{array}$ & $\begin{array}{l}\text { Dana köftelerine farklı } \\
\text { konsantrasyonlarda }(\% 0, \\
\% 0.25, \% 0.5 \text { ve } \% 1) \text { ve } \\
\text { farklı yöntemlerle (köfte } \\
\text { yüzeyine serpme ve } \\
\text { k1yma formülasyonuna } \\
\text { karıştırma) ekstrakt } \\
\text { eklenerek hazırlanan } \\
\text { örnekler } 150^{\circ} \mathrm{C} \text { ve } 190^{\circ} \mathrm{C} \\
\text { S1caklıklarda derin yağda } \\
\text { kızartılmıştır. }\end{array}$ & $\begin{array}{l}\text { Toplam HCA miktarının } 2.92 \mathrm{ng} / \mathrm{g} \text { ve } \\
\text { altında olduğu belirlenmiştir. Köfte } \\
\text { örneklerinde IQx }(1.47 \mathrm{ng} / \mathrm{g}) \text { ve PhIP } \\
(1.86 \mathrm{ng} / \mathrm{g}) \text { en yüksek seviyelerde } \\
\text { tespit edilirken reishi mantarı } \\
\text { ekstraktının toplam HCA oluşumunu } \\
\% 54.26-100 \text { aralığında inhibe ettiği } \\
\text { görülmüştür. }\end{array}$ & $\begin{array}{l}\text { Güzel, } \\
2019\end{array}$ \\
\hline
\end{tabular}




\section{Bazı Doğal Antioksidanların Et ve Et Ürünlerinde Heterosiklik Aromatik Amin Oluşumu Üzerine Etkileri}

\section{Sonuç}

Et ve et ürünlerinin birçok ülkede yüksek miktarda tüketilmesi ve epidemiyolojik çalışmalarla et tüketiminin yüksek olduğu ülkelerde çeşitli kanser türlerinin yaygın olduğunun belirlenmesiyle beraber, HCA bileşiklerinin tespiti ve önlenmesi önem kazanmıştır. Bununla beraber antioksidanların, serbest radikal reaksiyonlarını önleyici özellikleri nedeniyle son yıllarda HCA oluşumunu önleyebilme potansiyeline sahip olduğu düşüncesiyle doğal antioksidan özelliğe sahip katkıların kullanımı ve etkileri araştırılmaya başlanmıștır. Et ve et ürünlerinde çeşitli antioksidanların kullanımının HCA oluşumunu inhibe edebileceği ve bu sayede HCA bileşiklerinin neden olduğu mutajenik ve kanserojenik etkinin azalarak, sağlik üzerindeki olumsuz etkilerinden korunulabileceği görülmüştür. $\mathrm{Bu}$ amaçla antioksidan kaynağ 1 olarak özellikle gıda ekstraktları ve baharatlarla yapılan çalışmalar, kullanılan konsantrasyon, gıdanın pişirme sıcaklığı ve yöntemi gibi faktörlere de bağlı olarak çoğunlukla HCA oluşumunu beklendiği gibi azaltmış veya tamamen inhibe etmiștir. Çalıșmalar, gıda endüstrisinde kullanılan katkıların sadece lezzet verici ya da koruyucu olarak değil, aynı zamanda HCA gibi toksik bileşiklere karş1 koruyucu ajan olarak görev yapmasını sağlayabileceğini göstermektedir. $\mathrm{Bu}$ bağlamda, yeni ve güçlü doğal antioksidanların kullanımı ve HCA oluşumuna etkisi ile ilgili çalışmalar hala devam etmektedir.

\section{Teșekkür}

$\mathrm{Bu}$ çalı̧̧ma Ege Üniversitesi Bilimsel Araştırma Projeleri Koordinasyon Birimi tarafindan desteklenmiştir. Proje Numarası: FYL-2019-20887.

\section{Kaynaklar}

Alaejos, M. S., Ayala, J. H., González, V., Afonso, A. M. (2008) Analytical methods applied to the determination of heterocyclic aromatic amines in foods. Journal of Chromatography B, 862(1-2), $15-42$.

Adamson, R. H., Takayama, S., Sugimura, T., Thorgeirsson, U. P. (1994) Induction of hepatocellular carcinoma in nonhuman primates by the food mutagen 2-amino-3methylimidazo [4, 5-f] quinoline. Environmental Health Perspectives, 102(2), 190-193.

Barzegar, F., Kamankesh, M., Mohammadi, A. (2019) Heterocyclic aromatic amines in cooked food: A review on formation, health risk-toxicology and their analytical techniques. Food Chemistry, 280, 240-254.

Bastida, S., Sánchez-Muniz, F. J., Olivero, R., Pérez-Olleros, L., Ruiz-Roso, B., Jiménez-Colmenero, F. (2009) Antioxidant activity of Carob fruit extracts in cooked pork meat systems during chilled and frozen storage. Food Chemistry, 116(3), 748-754.

Buła, M., Przybylski, W., Jaworska, D., Kajak-Siemaszko, K. (2019) Formation of heterocyclic aromatic amines in relation to pork quality and heat treatment parameters. Food Chemistry, 276, 511-519.

Cárdenes, L., Ayala, J. H., Afonso, A. M., González, V. (2004) Solid-phase microextraction coupled with highperformance liquid chromatography for the analysis of heterocyclic aromatic amines. Journal of Chromatography A, 1030(1-2), 87-93.

Cheng, K. W., Wu, Q., Zheng, Z. P., Peng, X., Simon, J. E., Chen, F., Wang, M. (2007) Inhibitory effect of fruit extracts on the formation of heterocyclic amines. Journal of Agricultural and Food Chemistry, 55(25), 10359-10365.

Chiang, V. S. C., Quek, S. Y. (2017) The relationship of red meat with cancer: Effects of thermal processing and related physiological mechanisms. Critical Reviews in Food Science and Nutrition, 57(6), 1153-1173.

Damašius, J., Venskutonis, P. R., Ferracane, R., Fogliano, V. (2011) Assessment of the influence of some spice extracts on the formation of heterocyclic amines in meat. Food Chemistry, 126(1), 149-156

Felton, J. S., Jägerstad, M., Knize, M. G., Skog, K., \& Wakabayashi, K. (2000) Contents in foods, beverages and 


\section{Bazı Doğal Antioksidanların Et ve Et Ürünlerinde Heterosiklik Aromatik Amin Oluşumu Üzerine Etkileri}

tobacco. Contents in Foods, Beverages and Tobacco., 31-71.

Friedman, M., Zhu, L., Feinstein, Y., Ravishankar, S. (2009) Carvacrol facilitates heat-induced inactivation of Escherichia coli $\mathrm{O} 157$ : $\mathrm{H} 7$ and inhibits formation of heterocyclic amines in grilled ground beef patties. Journal of Agricultural and Food Chemistry, 57(5).

Gibis, M. (2007) Effect of oil marinades with garlic, onion, and lemon juice on the formation of heterocyclic aromatic amines in fried beef patties. Journal of Agricultural and Food Chemistry, 55(25), 10240-10247.

Gibis, M., Weiss, J. (2012) Antioxidant capacity and inhibitory effect of grape seed and rosemary extract in marinades on the formation of heterocyclic amines in fried beef patties. Food Chemistry, 134(2), 766-774.

Güçlü, K., Apak, R., Özyürek, M. (2009) Hidroksil ve Süperoksit Radikallerinin Süpürülmesine Dayalı Yeni Antioksidan Aktivite Tayin Yöntemlerinin Geliştirilmesi. Tübitak Proje, pp. 1-11.

Güzel, B. (2019) Reishi Mantarı Ekstraktının Köftede Heterosiklik Aromatik Aminlerin Oluşumu Üzerine Etkisi. Yüksek Lisans Tezi, Hacettepe Üniversitesi.

International Agency Research on CancerIARC (1993). Monographs on the evaluation of carcinogenic risk to humans: Some naturally occurring aromatic amines and mycotoxins (Vol. 56, pp. 163-242). Lyon, France: International Agency for Research on Cancer (IARC).

Jägerstad, M., Skog, K., Arvidsson, P., Solyakov, A. (1998) Chemistry, formation and occurrence of genotoxic heterocyclic amines identified in model systems and cooked foods. Zeitschrift für Lebensmitteluntersuchung undForschung A, 207(6), 419-427.

Jägerstad, M., Skog, K., Grivas, S., Olsson, K. (1991) Formation of heterocyclic amines using model systems. Mutation Research/Genetic Toxicology, 259(3-4), 219-233.
Jinap, S., Iqbal, S. Z., Selvam, R. M. (2015) Effect of selected local spices marinades on the reduction of heterocyclic amines in grilled beef (satay). LWT-Food Science and Technology, 63(2), 919-926.

Kikugawa, K. (1999) Involvement of free radicals in the formation of heterocyclic amines and prevention by antioxidants. Cancer Letters, 143(2), 123-126.

Keskekoglu, H., Uren, A. (2014) Inhibitory effects of pomegranate seed extract on the formation of heterocyclic aromatic amines in beef and chicken meatballs after cooking by four different methods. Meat Science, 96(4), 1446-1451.

Keskekoglu, H., Uren, A. (2017) Inhibitory effects of grape seed extract on the formation of heterocyclic aromatic amines in beef and chicken meatballs cooked by different techniques. International Journal of Food Properties, 20(sup1), S722-S734.

Krach, C., Sontag, G. (2000) Determination of some heterocyclic aromatic amines in soup cubes by ion-pair chromatography with coulometric electrode array detection. Analytica Chimica Acta, 417(1), 77-83.

Lan, C. M., Chen, B. H. (2002) Effects of soy sauce and sugar on the formation of heterocyclic amines in marinated foods. Food and Chemical Toxicology, 40(7), 989-1000.

Lan, C. M., Kao, T. H. Chen, B. H. (2004) Effects of heating time and antioxidants on the formation of heterocyclic amines in marinated foods. Journal of Chromatography B, 802(1), 27-37.

Macit, A. (2018) Zeytin Yaprağı Ekstraktının Somon Balığında Heterosiklik Aromatik Aminlerin Oluşumu Üzerine Etkisi. Yüksek Lisans Tezi, Hacettepe Üniversitesi.

Manabe, S., Suzuki, H., Wada, O., Ueki, A. (1993) Detection of the carcinogen 2amino-1-methyl-6-phenyl-imidazo [4, 5b] pyridine $(\mathrm{PhIP})$ in beer and wine. Carcinogenesis, 14(5), 899-901.

Melo, A., Viegas, O., Petisca, C., Pinho, O., Ferreira, I. M. (2008) Effect of beer/red wine marinades on the formation of heterocyclic aromatic amines in pan-fried 


\section{Bazı Doğal Antioksidanların Et ve Et Ürünlerinde Heterosiklik Aromatik Amin Oluşumu Üzerine Etkileri}

beef. Journal of Agricultural and Food Chemistry, 56(22), 10625-10632.

Monti, S. M., Ritieni, A., Sacchi, R., Skog, K., Borgen, E., Fogliano, V. (2001) Characterization of phenolic compounds in virgin olive oil and their effect on the formation of carcinogenic/mutagenic heterocyclic amines in a model system. Journal of Agricultural and Food chemistry, 49(8), 3969-3975.

Murkovic, M., Steinberger, D., Pfannhauser, W. (1998) Antioxidant spices reduce the formation of heterocyclic amines in fried meat. Zeitschrift für Lebensmitteluntersuchung undForschung A, 207(6), 477-480.

Naccari, C., Galceran, M. T., Moyano, E., Cristani, M., Siracusa, L., Trombetta, D. (2009) Presence of heterocyclic aromatic amines (HAs) in smoked "Provola" cheese from Calabria (Italy). Food and Chemical Toxicology, 47(2), 321-327.

Oz, F., Kaya, M. (2011a) The inhibitory effect of black pepper on formation of heterocyclic aromatic amines in high-fat meatball. Food Control, 22(3-4), 596600.

Oz, F., Kaya, M. (2011b) The inhibitory effect of red pepper on heterocyclic aromatic amines in fried beef Longissimus dorsi muscle. Journal of Food Processing and Preservation, 35(6), 806-812.

Oz, F., Kaban, G., Kaya, M. (2007) Effects of cooking methods on the formation of heterocyclic aromatic amines of two different species trout. Food Chemistry, 104(1), 67-72.

Öz, F., Kaya, M. (2007) Et ve et ürünlerinde heterosiklik aromatik amin oluşumunun engellenmesi. Atatürk Üniversitesi Ziraat Fakültesi Dergisi, 38(1), 121-126.

Pais, P., Knize, M. G. (2000) Chromatographic and related techniques for the determination of aromatic heterocyclic amines in foods. Journal of Chromatography B: Biomedical Sciences and Applications, 747(1-2), 139-169.

Pannala, A.S., Chan, T.S., O'Brien, P.J., RiceEvans, C.A. (2001) Flavonoid B-ring chemistry and antioxidant activity: Fast reaction kinetics. Biochemical and
Biophysical Research Communications, 282: 1161-1168.

Persson, E., Graziani, G., Ferracane, R., Fogliano, V., Skog, K. (2003) Influence of antioxidants in virgin olive oil on the formation of heterocyclic amines in fried beefburgers. Food and Chemical Toxicology, 41(11), 1587-1597.

Persson, E., Oroszvári, B. K., Tornberg, E., Sjöholm, I., Skog, K. (2008) Heterocyclic amine formation during frying of frozen beefburgers. International Journal of Food Science \& Technology, 43(1), 62-68.

Pezdirc, M., Žegura, B., Filipič, M. (2013) Genotoxicity and induction of DNA damage responsive genes by food-borne heterocyclic aromatic amines in human hepatoma HepG2 cells. Food and Chemical Toxicology, 59, 386-394.

Puangsombat, K., Smith, J. S. (2010) Inhibition of heterocyclic amine formation in beef patties by ethanolic extracts of rosemary. Journal of Food Science, 75(2), T40-T47.

Puangsombat, K., Jirapakkul, W., Smith, J. S. (2011) Inhibitory activity of Asian spices on heterocyclic amines formation in cooked beef patties. Journal of Food Science, 76(8), T174-T180.

Püssa, T. (2013) Toxicological issues associated with production and processing of meat. Meat Science, 95(4), 844-853.

Richling, E., Decker, C., Häring, D., Herderich, M., Schreier, P. (1997) Analysis of heterocyclic aromatic amines in wine by high-performance liquid chromatography-electrospray tandem mass spectrometry. Journal of Chromatography A, 791(1-2), 71-77.

Rounds, L., Havens, C. M., Feinstein, Y., Friedman, M., Ravishankar, S. (2012) Plant extracts, spices, and essential oils inactivate Escherichia coli O157: $\mathrm{H} 7$ and reduce formation of potentially carcinogenic heterocyclic amines in cooked beef patties. Journal of Agricultural and Food Chemistry, 60(14), 3792-3799.

Sabally, K., Sleno, L., Jauffrit, J. A., Iskandar, M. M., Kubow, S. (2016) Inhibitory 


\section{Bazı Doğal Antioksidanların Et ve Et Ürünlerinde Heterosiklik Aromatik Amin Oluşumu Üzerine Etkileri}

effects of apple peel polyphenol extract on the formation of heterocyclic amines in pan fried beef patties. Meat Science, $117,57-62$.

Schwarzenbach, R., Gubler, D. (1992) Detection of heterocyclic aromatic amines in food flavours. Journal of Chromatography A, 624(1-2), 491-495.

Skog, K. I., Jagerstad, I. M. (1993) Carbohydrates, especially mono and disaccharides in excess inhibit the formation of mutagenic heterocyclic amines during frying of meat. In: Waldbronn KW, Fenwick GR (eds) Food and Cancer Prevention. The Royal Society of Chemistry, Cambridge, pp 8791.

Skog, K. (1993) Cooking procedures and food mutagens: a literature review. Food and Chemical Toxicology, 31(9), 655-675.

Sugimura, T., Wakabayashi, K., Nakagama, H., Nagao, M. (2004) Heterocyclic amines: Mutagens/carcinogens produced during cooking of meat and fish. Cancer Science, 95(4), 290-299.

Szterk, A., Waszkiewicz-Robak, B. (2014) Influence of selected quality factors of beef on the profile and the quantity of heterocyclic aromatic amines during processing at high temperature. Meat Science, 96(3), 1177-1184.

Tengilimoglu-Metin, M. M., Kizil, M. (2017) Reducing effect of artichoke extract on heterocyclic aromatic amine formation in beef and chicken breast meat. Meat Science, 134, 68-75.

Tengilimoglu-Metin, M. M., Hamzalioglu, A., Gokmen, V., Kizil, M. (2017) Inhibitory effect of hawthorn extract on heterocyclic aromatic amine formation in beef and chicken breast meat. Food Research International, 99, 586-595.

Toribio, F., Moyano, E., Puignou, L., Galceran, M. T. (2002) Ion-trap tandem mass spectrometry for the determination of heterocyclic amines in food. Journal of Chromatography A, 948(1-2), 267281.

Tsen, S. Y., Ameri, F., Smith, J. S. (2006) Effects of rosemary extracts on the reduction of heterocyclic amines in beef patties. Journal of Food Science, 71(8), C469-C473.

Unal, K., Karakaya, M., Oz, F. (2018) The effects of different spices and fat types on the formation of heterocyclic aromatic amines in barbecued sucuk. Journal of the Science of Food and Agriculture, 98(2), 719-725.

Viegas, O., Amaro, L. F., Ferreira, I. M., Pinho, O. (2012) Inhibitory effect of antioxidant-rich marinades on the formation of heterocyclic aromatic amines in pan-fried beef. Journal of Agricultural and Food Chemistry, 60(24), 6235-6240.

Vitaglione, P., Fogliano, V. (2004) Use of antioxidants to minimize the human health risk associated to mutagenic/carcinogenic heterocyclic amines in food. Journal of Chromatography B, 802(1), 189-199.

Vitaglione, P., Monti, S., Ambrosino, P., Skog, K., Fogliano, V. (2002) Carotenoids from tomatoes inhibit heterocyclic amine formation. European Food Research and Technology, 215(2), 108-113.

Wakabayashi, K., Nagao, M., Esumi, H., Sugimura, T. (1992) Food-derived mutagens and carcinogens. Cancer Research, 52(7 Supplement), 2092s2098s.

Weisburger, J. H., Nagao, M., Wakabayashi, K., Oguri, A. (1994) Prevention of heterocyclic amine formation by tea and tea polyphenols. Cancer Letters, 83(1-2), 143-147.

Wolk, A. (2017) Potential health hazards of eating red meat. Journal of Internal Medicine, 281(2), 106-122.

Yang, D., He, Z., Gao, D., Qin, F., Deng, S., Wang, P., Zeng, M. (2019) Effects of smoking or baking procedures during sausage processing on the formation of heterocyclic amines measured using UPLC-MS/MS. Food Chemistry, 276, 195-201.

Zeng, M., Zhang, M., Chen, J., He, Z., Qin, F., $\mathrm{Hu}, \mathrm{C}$., Chen, J. (2017) UPLC-MS/MS and multivariate analysis of inhibition of heterocyclic amine profiles by black pepper and piperine in roast beef patties. 
Bazı Doğal Antioksidanların Et ve Et Ürünlerinde Heterosiklik Aromatik Amin Oluşumu Üzerine Etkileri

Chemometrics and Intelligent

Laboratory Systems, 168, 96-106.

Zimmerli, B., Rhyn, P., Zoller, O., Schlatter,

J. (2001) Occurrence of heterocyclic aromatic amines in the Swiss diet: analytical method, exposure estimation and risk assessment. Food Additives \& Contaminants, 18(6), 533-551. 